Abstract

\title{
Investigation of In Vitro Cytotoxic Effects of Montivipera xanthina on Healthy and Cancer Human Lung Cell Lines ${ }^{\dagger}$
}

\author{
Huzeyfe Huriyet *, Tolga Cavas, Ozgur Vatan and Nilufer Cinkilic \\ Department of Biology, Science and Art Faculty, Uludag University, Bursa 16059, Turkey; \\ tcavas@gmail.com (T.C.); ovatan@uludag.edu.tr (O.V.); aydemirn@uludağ.edu.tr (N.C.) \\ * Correspondence: huzobio@gmail.com; Tel.: +053-7223-5514 \\ + Presented at the 2nd International Conference on Natural Products for Cancer Prevention and Therapy, \\ Kayseri, Turkey, 8-11 November 2017.
}

Published: 14 November 2017

\begin{abstract}
Biotoxins have been used for therapeutic purposes in many cultures since ancient times. It is known that from simple to more complex organisms the animal kingdom contain poisons. Works in the field of anti-cancer seems to concentrate especially on bees, spiders, scorpions and snake venoms. In the present study, it was aimed to investigate the in vitro cytotoxic effects of Montivipera xanthina on normal and cancer human lung cell lines. For this purpose the cytotoxic effects of venoms collected from both species were investigated using XTT and Clonogenic assay on A549 human lung cancer and Beas-2B human healthy bronchial epithelial cell lines. In cytotoxicity tests it has been determined that venoms of $M$. xanthina concentration dependently decreased the viability of both A549 and Beas-2B cells. As a result of the XTT test, the IC50 values of the M. xanthina venom on A549 and Beas-2B were calculated as $1553 \mu \mathrm{g} / \mathrm{mL}$ and $2156 \mu \mathrm{g} / \mathrm{mL}$, respectively. In the clonogenic test, these values were determined as $2112 \mu \mathrm{g} / \mathrm{mL}$ and $2457 \mu \mathrm{g} / \mathrm{mL}$ for the A549 and Beas-2B cells, respectively.
\end{abstract}

Keywords: snake venom; anticancer; cytotoxicity

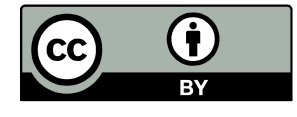

(C) 2017 by the authors. Licensee MDPI, Basel, Switzerland. This article is an open access article distributed under the terms and conditions of the Creative Commons Attribution (CC BY) license (http://creativecommons.org/licenses/by/4.0/). 